\title{
Hubungan Tingkat Pengetahuan dengan Karies Dentis pada Ibu Hamil di Posyandu Baiturrahman Kota Banda Aceh
}

\section{Correlation between Knowledge Level and Dental Caries in Pregnant Women at Integrated Services Post in Baiturrahman Banda Aceh City}

\author{
Munifah Abdat ${ }^{1}$ dan Dewi Ismail ${ }^{1}$ \\ 1) Departemen Ilmu Kedokteran Gigi Masyarakat Fakultas Kedokteran Gigi Unversitas Syiah Kuala, Aceh, Indonesia \\ Korespondensi: munifahabdat_dr@unsyiah.ac.id
}

Submitted: 8 Februari 2019, Revised: 9 April 2019, Accepted: 22 April 2019

https://doi.org/10.22435/jpppk.v3i1.1695

\begin{abstract}
Abstrak
Masa kehamilan merupakan masa perubahan fisiologis dan fisik tubuh termasuk rongga mulut, sementara pengetahuan ibu hamil terhadap pemeliharaan kesehatan gigi dan mulut masih relatif rendah. Perubahan rongga mulut pada ibu hamil antara lain meningkatnya resiko karies gigi, gingivitis dan penyakit periodontal, masih kurang diperhatikan. Tujuan penelitian ini adalah untuk mengetahui tingkat pengetahuan tentang kesehatan gigi dan mulut serta karies dentis pada ibu hamil di Posyandu. Pengambilan subyek penelitian dilakukan dengan teknik purposive sampling yang memenuhi kriteria inklusi dan eksklusi yaitu ibu hamil tanpa adanya riwayat penyakit sistemik dan berada di posyandu wilayah Baiturrahman kota Banda Aceh ketika dilakukan pengumpulan data. Teknik pengumpulan data dilakukan dengan pembagian kuisioner disertai pemeriksaan kondisi gigi menggunakan indeks DMF-T pada subyek penelitian. Hasil penelitian ini menunjukkan tingkat pengetahuan ibu hamil tentang pentingnya kesehatan gigi dan mulut masih kurang, hasil pemeriksaan DMF-T menunjukkan skor 6,9 (kategori sangat tinggi) dengan ditemukan karies gigi (decay) pada seluruh ibu hamil. Sejumlah $65 \%$ subyek penelitian mengaku tidak mendapat edukasi dari dokter kandungannya tentang kesehatan rongga mulut dan hubungannya dengan kehamilan. Berdasarkan uji korelasi menggunakan Pearson test disimpulkan bahwa terdapat hubungan signifikan negatif $(p=0,001)$ antara tingkat pengetahuan dan status karies pada ibu hamil, makin rendah pengetahuan ibu hamil maka makin tinggi status karies pada ibu hamil.
\end{abstract}

Kata kunci: ibu hamil, pengetahuan, karies dentis

\section{Abstract}

Pregnancy is a period of physiological and physical changes in the body including oral cavity, while knowledge of pregnant women about maintaining dental and oral health is still relatively low. Changes in the oral cavity in pregnant women include increases risk of dental caries, gingivitis and periodontal diseases that are less noticed. Purpose of study was to determine level of knowledge about oral health and dental caries of pregnant women at integrated Service Post. Subject of research was taken by purposive sampling technique that met the inclusion and exclusion criteria, namely pregnant women without a history of systemic disease and was in the posyandu in the Baiturrahman area of Banda Aceh city when data collection was carried out. Data collection techniques were carried out by distributing questionnaires along with examination of dental conditions using index DMF-T in the subjects. Results of this study indicate level of knowledge of pregnant women about the importance of dental and oral health is still lacking, results of DMF-T examination which is 6.9 (very high category) found dental caries (decay) in all subjects. $65 \%$ of subjects said that they did not get education from their obstetricians about the health of the oral cavity and its relationship to pregnancy. Based on the correlation test using Pearson test concluded there was a significant negative relationship $(p=0.001)$ between knowledge levels and caries status in pregnant women, the lower knowledge of pregnant women had low knowledge, in fact their caries status was high. 


\section{Pendahuluan}

Berdasarkan Riset Kesehatan Dasar (Riskesdas), prevalensi masalah gigi dan mulut di Indonesia tahun 2007, 2013 dan 2018 semakin meningkat. Kasus pada 2013 sebesar 25,9\% (meningkat 2,4\%) dan kasus 2018 sebesar 57,6\% (meningkat 44,9\%). Prevalensi masalah gigi dan mulut di atas prevalensi nasional sebanyak 16 provinsi diantaranya adalah Provinsi Aceh yaitu 30,5 persen. Kasus masalah gigi dan mulut di Provinsi Aceh, yang mendapatkan perawatan dan pengobatan dari tenaga medis gigi hanya 14 persen, termasuk ibu hamil pada tahun 2013 dan menurun menjadi $10,2 \%$ pada tahun 2018 , termasuk perilaku menyikat gigi secara benar masih rendah yaitu sebesar $2,8 \%{ }^{1,2}$

Penelitian yang dilakukan oleh Mascarehans P dkk (2003) telah menunjukkan bahwa perubahan kondisi periodontal ibu hamil dapat dihubungkan dengan perubahan kadar hormon steroid yang mempengaruhi vaskularisasi gingiva, mikrobia subgingiva, sel spesifik periodontal dan sistem imun lokal selama kehamilan. ${ }^{3}$ Dewasa ini perhatian masyarakat terhadap kesehatan ibu selama masa kehamilan semakin meningkat, tetapi tidak dibarengi kesehatan gigi dan mulut sehingga terlewatkan dari perhatian. Kurangnya perhatian terhadap kesehatan rongga mulut ini disebabkan karena kurangnya pengetahuan masyarakat sehingga masyarakat beranggapan bahwa kehamilan tidak ada hubungannya dengan keadaan rongga mulut. Ibu hamil tidak memahami bahwa kehamilan dapat mengalami perubahan hampir pada seluruh organ tubuh pada masa janin di dalam kandungan, termasuk rongga mulut, yang disebabkan karena adanya perubahan hormon. Perubahan hormonal yang terjadi selama kehamilan meliputi peningkatan hormon seks yaitu estrogen dan progesteron., ${ }^{4}$

Masalah utama kesehatan gigi dan mulut yang paling banyak dijumpai pada masyarakat adalah karies gigi dan penyakit periodontal. ${ }^{6}$ Berdasarkan pengamatan klinis, prevalensi penyakit periodontal selama kehamilan hasil beberapa penelitian bervariasi antara 20\%-100\%. Meskipun karies gigi secara umum mengalami penurunan di semua umur, namun hasil penelitian menunjukkan bahwa karies gigi tetap tinggi selama kehamilan yaitu sekitar 40-90\% wanita hamil menderita karies gigi di negara-negara berkembang. ${ }^{7}$ Tingginya kasus ini terjadi karena Infeksi periodontal dapat menyebabkan paparan plasenta-janin sehingga mempengaruhi kelahiran prematur dan berat badan lahir rendah. ${ }^{8}$

Penelitian ini bertujuan untuk mengetahui hubungan tingkat pengetahuan dan kejadian karies dentis pada ibu hamil di Posyandu wilayah Baiturrahman Banda Aceh.

\section{Metode}

Penelitian ini adalah observasional yang didesain secara cross-sectional. Penelitian dilaksanakan pada bulan Desember 2017 di 3 Posyandu yaitu Posyandu Peuniti, Seutui, dan Sukaramai di kecamatan Baiturrahman kota Banda Aceh. Populasi dalam penelitian ini adalah semua ibu hamil di Posyandu wilayah Baiturrahman Banda Aceh. Subyek yang digunakan dalam penelitian ini adalah 31 ibu hamil dari Posyandu Peuniti, Seutui, dan Sukaramai wilayah Baiturrahman Banda Aceh yang memenuhi kriteria inklusi. Pengambilan subyek penelitian ini dilakukan dengan teknik purposive sampling, yaitu memilih subyek diantara populasi berdasarkan kategori atau sifat yang diinginkan peneliti dan dengan pertimbangan tertentu. Kriteria inklusi penelitian ini adalah ibu hamil yang bersedia dan hadir di Posyandu dan tidak memiliki riwayat penyakit sistemik, dilakukan dengan menanyakan langsung pada subyek diawal menggunakan borang seleksi subyek serta kroscek data medis individu tiap subyek pada bidan di posyandu.

Izin penelitian dari Departemen IKGMP Fakultas Kedokteran Gigi Universitas Syiah Kuala, izin dari puskesmas Baiturrahman Banda Aceh, dan permohonan izin dari bidan desa wilayah Baiturrahman Banda Aceh maka semua subyek penelitian dikumpulkan dan setelah itu peneliti membagikan kuisioner sebagi instrument penelitian pada tiap subyek dan melakukan pemeriksaan (screening) gigi geligi dengan menggunakan indeks DMFT dan pemeriksaan OHI-S di posyandu Peuniti, Seutui, dan Sukaramai wilayah puskesmas Baiturrahman Banda Aceh. Jenis data yang digunakan dalam penelitian ini adalah data primer. Tingkat pengetahuan subyek didapat dari hasil olah data kuesioner yang harus diisi oleh semua subyek. Hasil data dari pemeriksaan tersebut dicatat kedalam 
form DMF-T yang disediakan dalam bentuk tabel.

Data dari hasil penelitian diolah melalui tahapan editing, coding, entri data dan cleaning. Data dianalisis univariat dan disajikan dalam bentuk tabel. Dilanjutkan analisis data bivariat berdasarkan uji korelasi menggunakan Pearson test, didapatkan persentase serta hubungan antara tingkat pengetahuan dan status karies pada ibu hamil.

\section{Hasil}

Subyek pada penelitian ini berjumlah 31 orang ibu hamil, masing-masing dibagikan kuesioner untuk mengetahui tingkat pengetahuan ibu hamil tentang kesehatan gigi dan mulut. Hasil penelitian mengenai tingkat pengetahuan ibu hamil terhadap kesehatan gigi dan mulut sebagaimana pada Tabel 1. Didapatkan bahwa tingkat pengetahuan ibu hamil terhadap pentingnya kesehatan rongga mulut masih tergolong rendah yang didominasi kategori sedang hingga kurang. Pemeriksaan gigi dan mulut melalui pengukuran indeks DMF-T dari $31 \mathrm{ibu}$ hamil menunjukkan kategori sangat tinggi (skor 6,9) dengan jumlah decay 158 gigi, missing 32 gigi, serta filling 26 gigi. Ditemukan sebanyak 20 ibu hamil memiliki gigi berlubang $\geq 4$, dengan rata-rata 4 gigi berlubang (Tabel 1).

Berdasarkan uji korelasi menggunakan Pearson test diperoleh nilai koefisien sebesar $-0,553$ dengan $p=0,001$ (Ho ditolak) pada hubungan tingkat pengetahuan kesehatan gigi dan mulut pada ibu hamil terhadap indeks DMF-T dan jumlah gigi berlubang sebsar $-0,441$ dan nilai signifikansi $p=$ 0,013. Berdasarkan hasil uji statistik artinya ada hubungan signifikan negatif antara rendahnya tingkat pengetahuan kesehatan rongga mulut dengan hasil indeks DMF-T yang kategorinya tinggi dan ada hubungan signifikan negatif antara tingkat pengetahuan kesehatan rongga mulut dengan jumlah gigi berlubang. Maknanya makin rendah tingkat pengetahuan ibu hamil tentang kesehatan gigi dan mulutnya maka semakin banyak jumlah giginya yang berlubang. Hasil uji korelasi sebagaimana pada Tabel 2.

\section{Pembahasan}

Kehamilan merupakan sebuah momen penting maka ibu hamil perlu dijaga kesehatannya. Di masyarakat kesehatan wanita selama masa kehamilan terutama kesehatan gigi dan mulut seringkali terlewat dari perhatian. Kurangnya perhatian ibu hamil terhadap kesehatan rongga mulut pada masa kehamilan dikarenakan kurangnya pengetahuan. Bahkan sebagian besar masyarakat masih beranggapan bahwa kehamilan tidak ada hubungannya dengan keadaan rongga mulut. $^{4}$

Hasil penelitian ini didapatkan bahwa tingkat pengetahuan kesehatan gigi dan mulut ibu hamil dengan persentase yang berbeda antar tiap kategori yaitu, kategori: 6,5\%, kategori sedang: $67,7 \%$ dan kategori kurang: $25,8 \%$, namun secara keseluruhan, tingkat pengetahuan ibu hamil terhadap pentingnya kesehatan rongga mulut masih tergolong rendah yang didominasi kategori sedang hingga rendah (Tabel 1). Selain itu sejumlah 65\% responden mengaku tidak mendapat edukasi dari dokter kandungannya tentang kesehatan rongga mulut dan hubungannya dengan kehamilan. Hal ini sesuai dengan penelitian yang dilakukan Shipra Gupta ${ }^{9}$ dkk (2015) yang menunjukkan bahwa 96\%

Tabel 1. Tingkat Pengetahuan Kesehatan Gigi dan Mulut pada Ibu Hamil dan kasus Gigi Berlubang (Decay)

\begin{tabular}{llcc}
\hline Pengetahuan dan Sikap & \multicolumn{2}{c}{ Total } \\
\cline { 2 - 3 } & & Jumlah (orang) & Persentase (\%) \\
\hline 1. & Kesehatan Gigi dan Mulut pada Ibu Hamil $(\mathbf{n}=\mathbf{3 1})$ & 2 orang & 6,5 \\
& Baik & 21 orang & 67,7 \\
$\quad$ Sedang & 8 orang & 25,8 \\
$\quad$ Kurang & & \\
2. Jumlah Gigi Berlubang (Decay) $(\mathbf{n}=\mathbf{3 1})$ & 11 orang & $35,5 \%$ \\
$\quad$ Rendah $(<4)$ & 20 orang & $64,5 \%$ \\
$\quad$ Tinggi $(\geq 4)$ & & \\
\hline
\end{tabular}


Tabel 2. Hubungan antara Tingkat Pengetahuan Kesehatan Gigi dan Mulut pada Ibu Hamil terhadap Indeks DMF-T dan Jumlah Gigi Berlubang

\begin{tabular}{lcll}
\hline \multicolumn{1}{c}{ Variabel } & Korelasi & \multicolumn{1}{c}{ Signifikansi } & \multicolumn{1}{c}{ Hasil } \\
\hline Indeks DMF-T & & & Ho ditolak \\
Penilaian Pengetahuan & $-0,553$ & $\begin{array}{l}p \text { value }=0,001 \\
p<0,05\end{array}$ & $\begin{array}{l}\text { Ha diterima } \\
=\text { Hipotesis terbukti }\end{array}$ \\
$\begin{array}{l}\text { Jumlah Gigi Berlubang (Decay) } \\
\text { Penilaian Pengetahuan }\end{array}$ & & & Ho ditolak \\
& $-0,441$ & $\begin{array}{l}p \text { value }=0,013 \\
p<0,05\end{array}$ & Ha diterima \\
\hline
\end{tabular}

ibu hamil tidak mendapatkan edukasi tentang kesehatan rongga mulut terkait kondisi kehamilan oleh dokter kandungan mereka, yang berdampak pada rendahnya tingkat pengetahuan kesehatan gigi dan mulut pada ibu hamil.

Hasil perhitungan indeks DMF-T pada penelitian ini menunjukkan nilai sebesar 6,9 , yang mana termasuk ke kategori sangat tinggi berdasarkan klasifikasi WHO $(>6,6)$. Sejalan dengan hasil ini, penelitian Chawla $^{10}$ dkk menunjukkan nilai ratarata DMF-T pada ibu hamil adalah sebesar 11,5, sedangkan penelitian yang dilakukan Kateeb dan Momany ${ }^{11}$ menunjukkan nilai rata-rata DMF-T pada ibu hamil yang lebih tinggi yaitu sebesar 15,5. Kedua hasil penelitian tersebut sama dengan penelitian ini yaitu angka DMF-T masuk kategori sangat tinggi.

Tabel 1 menunjukkan jumlah gigi berlubang $\geq 4$ gigi dialami oleh 20 ibu hamil dengan rata-rata 4 gigi pada setiap ibu hamil, sedangkan $11 \mathrm{ibu}$ hamil lainnya memiliki jumlah gigi berlubang $<4$ dengan rata-rata 3 gigi. Dapat dilihat dari hasil tersebut, bahwa seluruh ibu hamil memiliki gigi berlubang dan lebih dari setengah ibu hamil memiliki ratarata gigi berlubang lebih dari sama dengan 4 gigi, yang menandakan bahwa masih rendahnya tingkat kesadaran ibu hamil untuk melakukan pemeliharaan dan perawatan terhadap kondisi rongga mulutnya, terutama pada gigi geligi yang berlubang. Sejalan dengan hal tersebut, penelitian Ingrida $^{12} \mathrm{dkk}$ menyebutkan bahwa seluruh responden ibu hamil yaitu 1070 orang (100\%) ibu hamil memiliki gigi berlubang di rongga mulutnya dengan rata- rata 11-12 gigi. Pada penelitian yang dilakukan Azofeifa ${ }^{13} \mathrm{dkk}$ diperoleh hasil bahwa prevalensi gigi berlubang (decay) pada ibu hamil adalah sebesar $87,2 \%$.

Berdasarkan Tabel 2 didapatkan bahwa terdapat hubungan antara tingkat pengetahuan kesehatan rongga mulut pada ibu hamil terhadap indeks DMFT, dengan signifikansi $p=-0,553$ yang menandakan semakin rendah tingkat pengetahuan, maka semakin tinggi nilai DMFT pada responden. Berdasarkan Tabel 2 didapatkan hubungan antara tingkat pengetahuan tentang kesehatan gigi mulut pada ibu hamil terhadap jumlah gigi berlubang, dengan nilai signifikansi $p=-0,441$ yang menemukan bahwa semakin rendah tingkat pengetahuan ternyata jumlah gigiberlubang padaibuhamil semakin banyak. Gaszynska $^{14}$ (2015) menyebutkan bahwa rendahnya tingkat pengetahuan kesehatan rongga mulut berdampak pada turut rendahnya kondisi kesehatan rongga mulut. Masalah rendahnya pengetahuan $\mathrm{ibu}$ tersebut terus berlanjut hingga tumbuh gigi sulung anaknya. Hasil penelitan Munifah Abdat ${ }^{15}$ (2018) yang dilakukan pada 33 orang ibu di Banda Aceh menunjukkan sebesar 3 orang ibu saja (9\%) dari seluruh subjek memiliki tingkat pengetahuan dan sikap yang baik, 20 orang ibu (61\%) memiliki tingkat pengetahuan yang cukup dan 10 orang ibu $(30 \%)$ memiliki tingkat pengetahuan yang kurang mengenai kesehatan gigi dan mulut baik untuk dirinya maupun anaknya.

Rendahnya tingkat pengetahuan meliputi motivasi serta kesadaran ibu hamil tentang pentingnya menjaga kebersihan rongga mulut 
dengan cara menyikat gigi secara teratur dan melakukan pemeriksaan ke dokter gigi secara berkala. Peran tenaga kesehatan lain seperti dokter kandungan dan bidan tidak kalah penting dalam turut serta memperhatikan kesehatan gigi dan mulut ibu hamil sebagai bagian dari kesehatan tubuh ibu secara umum. Yakni berintegrasi dalam pelayanan kesehatan ibu hamil dengan melakukan prosedur rujukan ke dokter gigi selama masa kehamilan.

\section{Kesimpulan}

Berdasarkan hasil analisa data yang telah dilakukan dapat disimpulkan bahwa pengetahuan dan kesadaran ibu hamil terhadap pentingnya kesehatan gigi dan mulut masih tergolong rendah dan didapati skor DMF-T=6,9 (kategori sangat tinggi), ditemukan tidak satupun dari $31 \mathrm{ibu}$ hamil tersebut yang bebas karies bahkan lebih dari setengah ibu hamil memiliki rata-rata gigi berlubang $\geq 4$ gigi. Dilanjutkan dengan uji korelasi Pearson yang menunjukkan bahwa terdapat hubungan antara tingkat pengetahuan ibu hamil terhadap indeks DMFT dimana semakin rendah tingkat pengetahuan maka semakin tinggi indeks DMF-T.

\section{Saran}

Untuk memaksimalkan hasil penelitian ini, disarankan dilakukan penelitian lebih lanjut dengan jumlah subjek yang lebih banyak dan lingkup yang luas, sehingga dapat mewakili semua populasi guna mengetahui hubungan tingkat pengetahuan dan karies dentis pada ibu hamil. Kondisi gigi dan mulut ibu selama kehamilan perlu diperhatikan oleh para petugas kesehatan sehingga tingkat kesehatan ibu dan janin lebih baik. Perlu adanya integrasi antara dokter kandungan, bidan dan dokter gigi kedepannya dalam memberikan pelayanan terhadap ibu hamil.

\section{Daftar Rujukan}

1. Departemen Kesehatan Republik Indonesia. Riset Kesehatan Dasar (Riskesdas) 2013. Jakarta: Badan Penelitian dan Pengembangan Kesehatan Kementrian Kesehatan RI; 2013.

2. Departemen Kesehatan Republik Indonesia. Riset Kesehatan Dasar (Riskesdas) 2018. Jakarta: Badan Penelitian dan Pengembangan Kesehatan Kementrian Kesehatan RI; 2018.
3. Mascarehans P. Influence of Sex Hormones of Periodontium. $J$ Clin Periodontal 2003;30(1):671-81.

4. Apriasari MA, Hasbullah DP. Prevalensi Gingivitis dan Epulis Gravidarum pada Wanita Hamil Trimester ke-tiga di RSUD Banjarbaru (Januari-Juni 2012) Departemen Penyakit Mulut. Dentino Jurnal Kedokteran Gigi 2012;1(1):129-35.

5. Gajendra S, Kumar JV. Oral Health and Pregnancy: A Review. $N$ Y State Dent $J$ 2004;70(1):40-4.

6. Soulissa AG. Hubungan Kehamilan dan Penyakit Periodontal. Jurnal PDGI 2014; 63(3):71-77.

7. Shamsi M, Hidarnia A, Niknami S, Rafiee M, Karimi M. Oral health during pregnancy: A study from women with pregnancy. Dent Res $J$ 2013;10(3):409-410.

8. Bobetsis YA, Barros SP, Offenbacher S. Exploring the relationship between periodontal disease and pregnancy complications. Journal of the American Dental Association 2006;137(1):7-13.

9. Gupta S, Jain A, Mohan, Bhaskar N. Comparative Evaluation of Oral Health Knowledge, Practices and Attitude of Pregnant and Non-Pregnant Women, and Their Awareness Regarding Adverse Pregnancy Outcomes. Journal of Clinical and Diagnostic Research. 2015: 9 (11): 26-32.

10. Chawla $\mathrm{R}$, Shetiya $\mathrm{S}$, Agarwal $\mathrm{D}$, et al. Knowledge, Attitude, and Practice of Pregnant Women regarding Oral Health Status and Treatment Needs following Oral Health Education in Pune District of Maharashtra: A Longitudinal Hospital-based Study. J Contemp Dent Pract 2017;18(5):371-77.

11. Kateeb E, Momany E. Dental caries experience and associated risk indicators among Palestinian pregnant women in the Jerusalem area: a crosssectional study. BMC Oral Health 2018;18:17077.

12. Vasiliauskiene I, Milciuviene S, Bendoraitiene E, et al. Dynamics of Pregnant Women's Oral Health Status during Preventive Programme. Stomatologija, Baltic Dental and Maxillofacial Journal 2007;9:129-36. 
13. Azofeifa A, Yeung LF, Alverson CJ, BeltránAguilar E. Dental caries and periodontal disease among U.S. pregnant women and nonpregnant women of reproductive age, National Health and Nutrition Examination Survey, 1999-2004. J Public Health Dent 2016;76(4):320-29.

14. Gaszynska E, Klepacz-Szewczyk J, Trafalska E, Garus-Pakowska A, Szatko F. Dental awareness and oral health of pregnant women in poland. Int J Occup Med Environ Health 2015;28(3):60311.

15. Abdat, Munifah. Pengetahuan dan Sikap Ibu Mengenai Gigi Sulung Anaknya Serta Kemauan Melakukan Perawatan. Cakradonya Dental Journal. 2018;10(1):18-26. 